\title{
A new species of Fernandezina (Araneae, Palpimanidae) from southern Brazil
}

\author{
Ricardo Ott ${ }^{1} \&$ Ana Paula Ott ${ }^{2}$
}

1. Museu de Ciências Naturais, Fundação Zoobotânica do Rio Grande do Sul. Rua Dr. Salvador França, 1427, 90690-000 Porto Alegre, RS, Brazil. (rott@fzb.rs.gov.br)

2. Departamento de Fitossanidade, Faculdade de Agronomia, Universidade Federal do Rio Grande do Sul. Av. Bento Gonçalves, 7712, 91540-000, Porto Alegre, RS, Brazil.

\begin{abstract}
A new species of Fernandezina Birabén, 1951, F. nica sp. nov. is described from Rio Grande do Sul state, in southern Brazil. Fernandezina pulchra Birabén, 1951, is registered for Brazil and a new geographic record in Brazil is presented for F. pelta Platnick, 1975.
\end{abstract}

KEYWORDS. Neotropical Region, Brazil, spiders, taxonomy.

RESUMO. Espécie nova de Fernandezina (Araneae, Palpimanidae) do sul do Brasil. Uma espécie nova de Fernandezina Birabén, 1951, F. nica sp. nov. é descrita do estado do Rio Grande do Sul, no sul do Brasil. Fernandezina pulchra Birabén, 1951, é registrada para o Brasil e um novo registro geográfico, no Brasil, é apresentado para F. pelta Platnick, 1975.

PALAVRAS-CHAVE. Região Neotropical, Brasil, aranhas, taxonomia.

The genus Fernandezina Birabén, 1951 comprises 10 species, all from South America (PlatnICK, 2014). Larger revisions of the genus were presented by PLATNICK (1975) and Platnick et al. (1999). As proposed by Platnick (1975) the genus can be recognized by the unexpanded femur of males and females and by the posteriorly extended abdominal dorsal scutum of males.

The most recent work on this genus was presented by Piacentini et al. (2013) who described the female of $F$. pulchra Birabén, 1951 and provided copious illustrations for both sexes of the species. Based on the evidence provided by the above cited authors, mainly regarding the dorsal abdominal chevron pattern and the illustrations of the male palp of F. pulchra, it was possible to recognize that specimens from south Brazil (which were long regarded as possibly belonging to F. pulchra) actually belong to an undescribed species.

In this work is described a new species of Fernadezina from Rio Grande do Sul state, Brazil, collected in araucaria forests in São Francisco de Paula municipality. The first records of F. pulchra for Brazil and new distribution data of F. pelta Platnick, 1975 in this country are presented.

\section{MATERIAL AND METHODS}

The specimens examined are deposited in the arachnological collection of the Museu de Ciências Naturais, Fundação Zoobotânica do Rio Grande do Sul (MCN; R. Ott) and Museu de Ciências e Tecnologia da Pontifícia Universidade Católica do Rio Grande do Sul (MCTP; A. A. Lise), both in Porto Alegre, Rio Grande do Sul, Brazil. The description format follows Platnick et al. (1999). The female genitalia were dissected and digested using $\mathrm{KOH} 10 \%$ and then submerged in clove oil for observation under transmited light microscopy.
Incident light images were taken through a stereomicroscope with attached camera and processed with Helicon Focus multi-range program. Transmitted light images of female genitalia were taken with a compound microscope using a digital camera and also processed with Helicon Focus. Drawings were made using printed images as models and compound microscope and stereomicroscope as three dimensional shape confirmation tools. Latitude and longitude data of the municipalities were taken from Google Earth. Measurements are in millimeters.

\section{Fernandezina Birabén, 1951}

Fernadezina BirabÉn, 1951:545; Platnick, 1975:26; 2014; Platnick et al., 1999:7; PiACENTINI et al., 2013:497.

Type-species: Fernadezina pulchra by original designation (BIRABÉN, 1951:546).

\section{Fernandezina nica sp. nov.}

(Figs 1-14)

Type material. Holotype $\widehat{\delta}$ from CPCN Pró-Mata (29²8’51.75”'S; 50¹0’27.25”), São Francisco de Paula, Rio Grande do Sul, Brazil, 02.II.2001, R. Ott leg., deposited in MCN ARA 49746 (sample 4 NEB 1-1; pitfall trap). Paratypes: ㅇ , 11.X.2001 (MCN ARA 49747; sample 12 ARA 2-5); + , 15.XII.2001 (MCN ARA 49748; sample

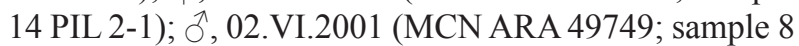
ARB 2-5); Ô, 07.VII.2001 (MCTP 37426; sample 9 ARB 1-2); ㅇ, 02.VI.2001 (MCTP 37427; sample 8 ARA 2-3); all same location, collector and collection methodology as the holotype.

Etymology. The noun in aposition is a portuguese word for "impertinency".

Diagnosis. Males of F. nica sp. nov. are close to those of F. pelta, F. pulchra and F. maldonado Platnick, 


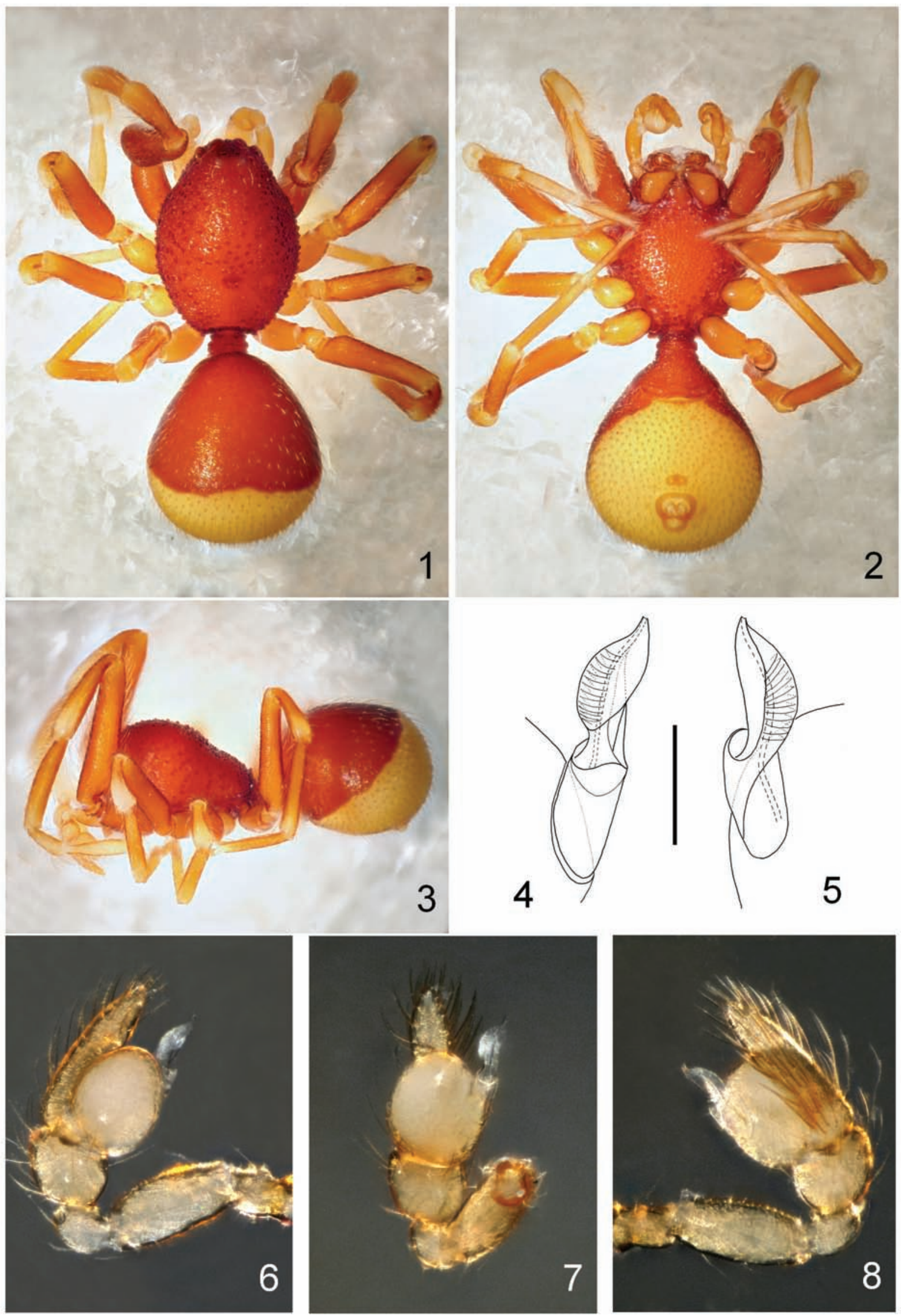

Figs 1-8. Fernandezina nica sp. nov. Holotype đ̊ (MCN ARA 49746): 1, dorsal; 2, ventral; 3, lateral. Paratype $\widehat{\jmath}$ (MCN ARA 49749), embolus: 4, ventral; 5, retrolateral. Palp: 6, prolateral; 7, ventral; 8, retrolateral. Scales: 4, 5, $0.2 \mathrm{~mm}$. Total length of pictured specimen (cefalothorax + abdomen): $2.79 \mathrm{~mm}$. 

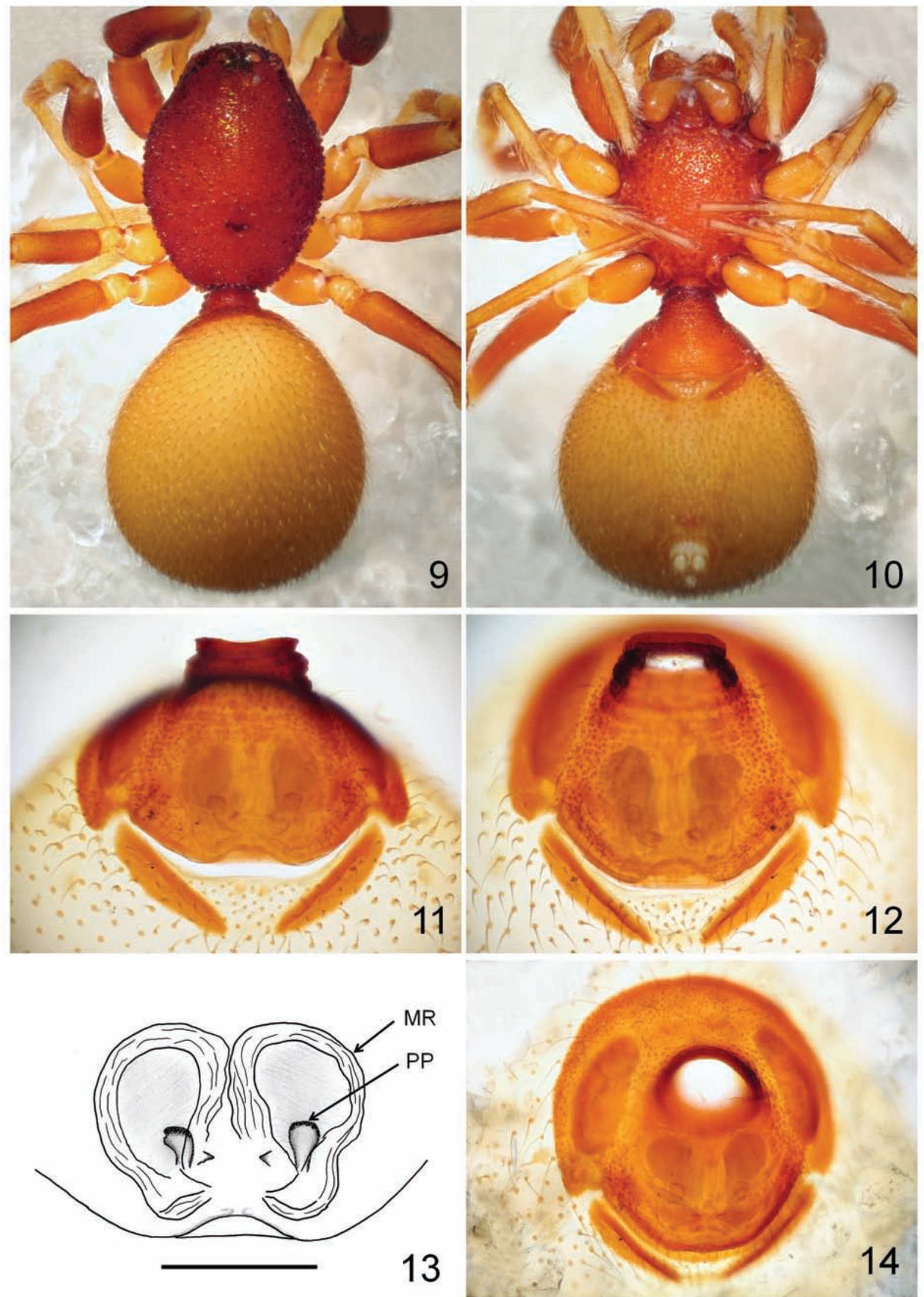

Figs 9-14. Fernandezina nica sp. nov. Paratype $q$ (MCN ARA 49747): 9, dorsal; 10, ventral. Paratype $\odot$ (MCN ARA 49748), epigastric scutum: 11, dorsal; 12, ventral. Internal genitalia: 13, dorsal; 14, ventral (MR, median receptaculum; PP, pore plate). Scales: $13,0.25 \mathrm{~mm}$. Total length of pictured specimen (cefalothorax + abdomen): 3,29 mm. 
Grismado \& Ramirez, 1999 in the shape of the male palpal bulb; the new species can be distinguished from the above cited species by the absence of any color pattern on the dorsum of the abdomen (Fig. 1); the males of F. nica sp. nov. are also distingished from those of F. pulchra by the larger bulb and proportionally smaller embolus and from $F$. pelta and F. maldonado by the longer distance between the basal edge and the base of the embolus (Figs 4-8), see also Platnick et al. (1999:10). Females are close to F. dasilvai Platnick, Grismado \& Ramirez, 1999 in the shape of the genitalia (Figs 11-14; see also Platnick et al., 1999:11, figs. 26-28 for F. dasilvai) but differ from this species by the absence on claw tufts in legs II-IV; they can be also recognized by the absence of any color pattern on the dorsum of the abdomen (Fig. 9).

Male (holotype). Total length 2.79. Carapace 1.39. long, 1.00. wide. Femur I 1.22 long, 0.31 high. Posterior median eyes separated by about their diameter. Carapace with large and small granules, large ones in somewhat radial rows; carapace border denticles as large as large granules of carapace (Figs 1, 9; similar to F. pelta, Figs 16, 17; see also PlatNick, 1975:28, fig. 80). Sternum also with large and small granules, larger ones located closer to lateral edges (Figs 2, 10; similar to F. pelta, see PiACENTINI et al., 2013:497, figs. 5c, 5f). Paturon lateral ridge present, stronger on basal half of chelicerae. Sclerotized portions of body red-brown; abdominal scutum covering about $80 \%$ of dorsum; unsclerotized portion of dorsum yellowish, no markings visible (Figs 1, 3), venter uniformly yellowish (Fig. 2). Palpal femur not thickened; tibia globose, slightly narrower than bulb (Figs 6-8). Embolus basal ledge close to its half-length (Figs 4-8). Embolus almost straight, distal tip not reaching cymbium distal end (Figs 4-8). Legs orange-brown, patellae color faded distally, remarkably so on leg II (Fig. 3). Tarsi II-IV without claw tufts.

Female (paratype MCN ARA 49747). Total length 3.29. Carapace 1.57 long, 1.14 wide. Femur I 1.48 long, 0.36 high. Posterior median eyes as in male (Fig. 9). Chelicerae as in male. Sclerotized parts color as in male; abdominal scutum restricted to anterior portion of abdomen around pedicel; abdominal pattern as in male (Figs 9, 10). Epigastric furrow area with two slender, sclerotized lateral patches behind epigastric furrow (Figs 10-12). Female internal genitalia with paired, relatively large, globose median receptacula (somewhat squared in porsterior view), dorsally directed; basal stalks of median receptaculum membranous, ending at cuticular screrotized v-shaped structures (Figs 11-14); posterior lobes originating at basal portion of median receptacula; distal portion bearing pore plate (Figs 11-14); uterus externus inconspicuous, apparently inside small cavity delimited ventrally by posterior border of scutum, dorsally by arched, semidomed sclerotized cover that is anteriorly and laterally fused to abdominal scutum (Figs 11-13).

Variation: males, total lenght $2.50-2.85$, carapace length 1.26-1.39; females, total lenght 3.24-3.77, carapace length 1.49-1.62.
Other material examined. $\widehat{\text { Oे }}$, 25.X.2000, (MCN ARA 49750; sample TRA 2-1); 今̂, 23.XI.2000 (MCN ARA 49751; sample TRA 2-4); $\hat{\partial}$, 15.XII.2001 (MCN ARA 49752; sample 14 NEB 2-5); ð̊, 18.V.2002 (MCN ARA 49753; sample 18 ARA 2-3); + , 02.VI.2001 (MCN ARA 49754; sample 8 NEB 2-1); ㅇ, 02.II.2001 (MCN ARA 40755; sample 4 ARA 2-4); + , 02.I.2001 (MCN ARA 49756; sample 3 ARA 2-1); + , 02.I.2001 (MCN ARA 49757; sample TRA 2-3); + , 13.XI.2001 (MCN ARA 49758; sample 13 ARA 2-3); all same location, collector and collection methodology as the holotype.

Distribution. Known only from the type locality.

Natural History. Collected at the ground of secondary and well preserved Araucaria forests areas on CPCN PróMata in 850-950 m altitude. None of the specimens listed above were collected at Pinus silviculture areas present on the same site and also sampled along 20 months with the same intensity as primary and secondary areas.

\section{Fernadezina pelta Platnick, 1975}

(Figs 15, 16)

Fernandezina pelta Platnick, 1975:28, figs 80, 85-89. Male holotype from Viçosa (2045'18'S, 4252'27’W), Minas Gerais, Brazil, deposited in American Museum of Natural History; not examined.

New records. BRAZIL, Rio de Janeiro: Campos dos Goytacazes $\left(21^{\circ} 45^{\prime} 42^{\prime}\right.$ S, 48 $\left.8^{\circ} 13^{\prime} 14^{\prime} \mathrm{W}\right), 2$, 13.VIII.2003, C. C. L. Teixeira leg. (MCN ARA 38692);

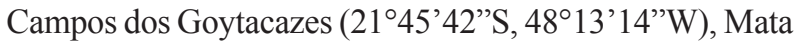

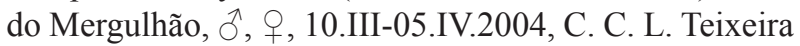
leg. (MCN ARA 43447; M. A. L. Marques det.).

Note. The abdomen coloration pattern of the examined specimens of $F$. pelta is close to the description for F. tijuca Ramirez \& Grismado, 1996 provided by RAMirez \& GRISMAdo (1996:118), “One brown area on each side of abdomen, leaving a narrow cream strip on unsclerotized dorsum"; although, in the male of $F$. pelta the cream strip is located under the scutum (Fig. 15); in male and females the abdominal dorsal cream colored strip is constricted somewhat in its posterior third (Figs 15, 16). However, the male palp bulbs of F. pelta and F. tijuca are very distinctive (see Platnick, 1975:29, figs. 86, 87 and RAmirez \& Grismado, 1996:118, figs 1, 2).

Distribution. States of Minas Gerais and Rio de Janeiro, Brazil.

\section{Fernandezina pulchra Birabén, 1951}

Fernandezina pulchra BIRABÉn, 1951:546, figs 1-3. Male holotype from Laguna Yema $\left(24^{\circ} 15^{\prime} 11^{\prime \prime} \mathrm{S}, 61^{\circ} 14^{\prime} 16^{\prime} \mathrm{W}\right)$, Formosa, Argentina, deposited in Museo Argentino de Ciencias Naturales "Bernardino Rivadavia”, not examined; Platnick, 1975:27; Platnick et al., 1999: 10, figs 32, 33; Piacentini et al., 2013:499, figs 5-6.

New Record. BRAZIL, Goiás: Minaçu (1331'44”'s, 4813'14”'W), Hidrelétrica Serra da Mesa, ô, 18-30. XI.1996, A. A. Bonaldo leg. (MCN ARA 27864). 

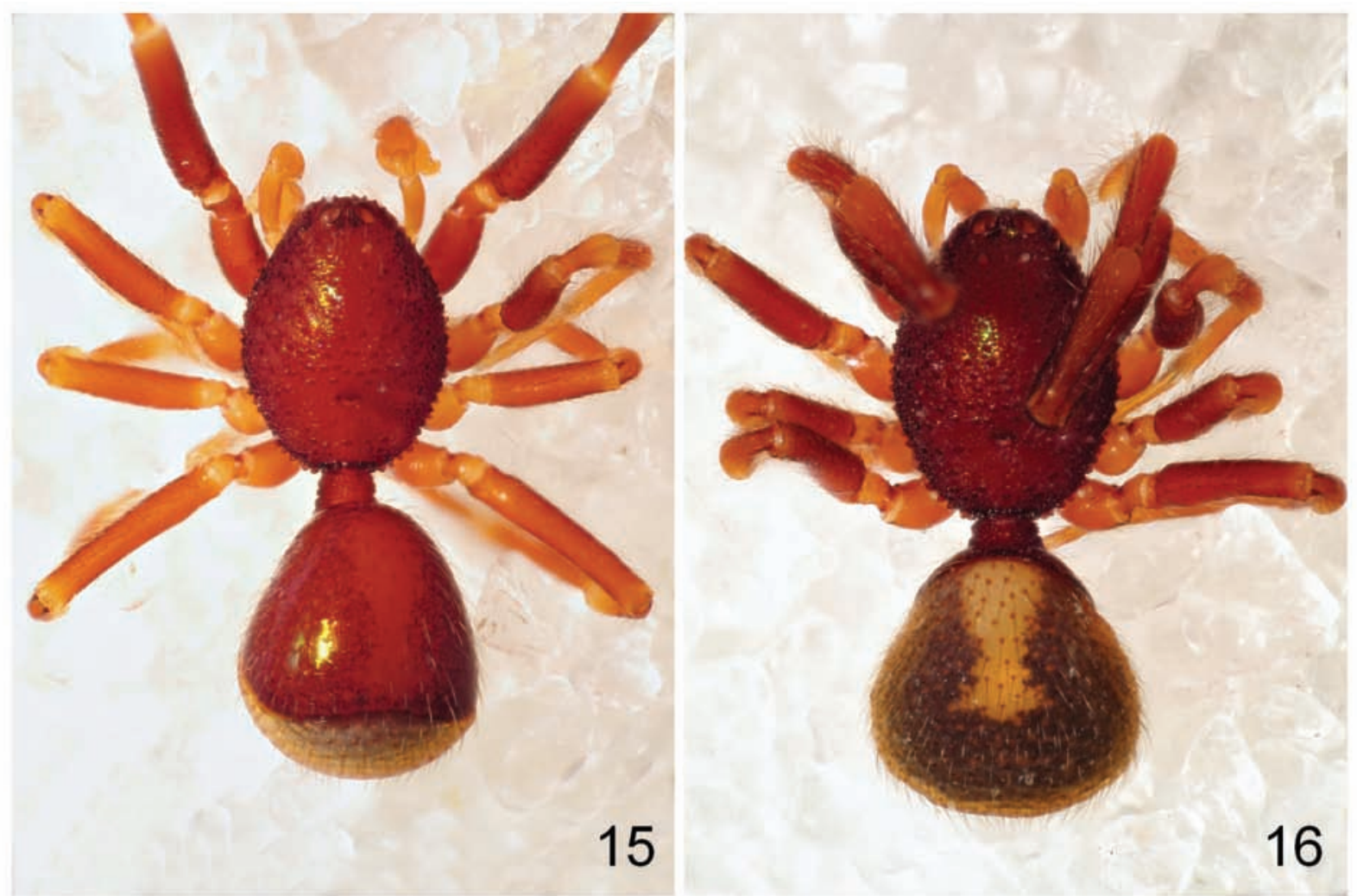

Figs 15, 16. Fernandezina pelta Platnick, 1975 (MCN 43447): 15, §̊, dorsal; 16, 9 , dorsal. Total length of pictured specimens (cefalothorax + abdomen): 15, $2.27 \mathrm{~mm} ; 16,2.34 \mathrm{~mm}$.

Distribution: state of Goiás, Brazil; department of Santa Cruz, Bolívia; province of Formosa, Argentina.

Acknowledgements. To Arno A. Lise, curator MCTP for the loan of material. To anonymous reviewers for the helpfull comments on the manuscript. The material examined in this work is part of the doctoral thesis of the author.

\section{REFERENCES}

Birabén, M. 1951. Fernandezina, nuevo género de Palpimanidae (Araneae). Acta Zoologica Lilloana 12:545-549.

Piacentini L. N.; Ávila Calero, S. L.; Pérez, M. E. \& Grismado, C. J. 2013. The first palpimanid spiders from Bolivia: two new species of the genus Otiothops MacLeay, and the female of Fernandezina pulchra Birabén (Araneae: Palpimanidae: Otiothopinae). Zootaxa 3619:491-500.
Platnick, N. I. 1975. A revision of the palpimanid spiders of the new subfamily Otiothopinae (Araneae, Palpimanidae). American Museum Novitates 2562:1-32.

. 2014. The world spider catalog, version 14.5. New York, American Museum of Natural History. Available at $<$ http://research. amnh.org/iz/spiders/catalog>. Accessed on 24 March 2014.

Platnick, N. I.; Grismado, C. J. \& Ramírez, M. J. 1999. On the genera of the spider subfamily Otiothopinae (Araneae, Palpimanidae). American Museum Novitates 3257:1-25.

Ramírez, M. J. \& Grismado, C. J. 1996. A new Fernandezina from Brazil (Araneae, Palpimanidae). Iheringia, Série Zoologia (86):117-119. 